\title{
The Development of Urban Intelligent Growth Plan Based on Analytic Hierarchy Process
}

\author{
Jian Liu \\ School of North China Electric Power University, Baoding 071000, China \\ 1766937377@qq.com
}

Keywords: Smart Growth, Analytic Hierarchy Process, Gray Forecast.

\begin{abstract}
In this paper, we set up two models - the indicator-determining model, the comprehensive estimation model, to evaluate the current urban smart growth and redesigning optimization schemes for urban smart growth. The whole work is dependent on the calculation of CI--the success rate of urban smart growth. Firstly, we divide the factors influencing the smart growth of city into three categories--the level of economic prosperity $\left(E_{0}\right)$, the extent of social equity $\left(E_{1}\right)$, the degree of environmental sustainability $\left(E_{2}\right)$, which are refined to ten indexes to measure CI. Meanwhile, the value of $\mathrm{CI}$ is obtained through the application of Analytic Hierarchy Process to the ten indexes. Secondly, we use comprehensive estimation model to evaluate the values of $E_{0}$ / $E_{1}$ / E2 of Jiayuguan City and Salt Lake City located in Asia and America in 2016 respectively. Via the calculation of the equations of CI, the results are 0.7249 and 0.6721 , which indicates that there are many aspects need to be improved in their current urbanization. Finally, based on the analyses of the two cities above, we schedule six set of optimization schemes which enhance the smart growth of the city from six aspects.
\end{abstract}

\section{Introduction}

In the case of implementing urban smart growth plan to realize economic prosperity and social equity, and build a better home of sustainable development, the first priority is to determine index of measuring the success rate of urban smart growth. Secondly, since the smart growth involves these aspects: economic prosperity, social equity and environmental sustainability, we need to extract key factors to measure the success rate of urban smart growth plan.

\section{Index-determining and evaluation of the Smart Growth Model[1][2]}

\subsection{Determination of equation calculating the success rate of smart growth}

The focus of smart growth is to construct sustainable city which is economically prosperous socially equitable and environmentally sustainable. Therefore, we focus on the ten principles related to the urban smart growth. We analyze the economic development, per capital housing area,architecture's design, the utilization of mixed land and greening area and so on. And we adopt the degree of economic prosperity, social equity and environmental sustainability to measure the success rate of urban smart growth quantitatively. Via analysis and judgment, we draw the conclusion: The degree of economic prosperity, social equity and environmental sustainability are important index to measure success rate of smart growth. The equation to calculate the success rate of smart growth can be determined:

$$
C I=\eta_{0} E_{0}+\eta_{1} E_{1}+\eta_{2} E_{2}
$$

Among them, $C I$ stands for the success rate of smart growth. $E_{0} / E_{1} / E_{2}$ represent the degree of economic prosperity, the degree of social equity and the degree of environmental sustainability respectively.

\subsection{Calculation result of the success rate of urban smart growth}

Furthermore, we calculate the weight of the degree of economic prosperity,the degree of social equity and the degree of environmental sustainability of promoting the success rate of urban smart growth based on analytic hierarchy process (Table 1). 
Table.1 The weight of the indexes of the degree of success.

\begin{tabular}{|c|c|c|c|}
\hline $\begin{array}{c}\text { Index } \\
\text { layer }\end{array}$ & Economic basis & Social development & Environmental sustainability \\
\hline Weight & 0.4280 & 0.3030 & 0.2690 \\
\hline
\end{tabular}

Based on table 1,we use decisive indexes to indicate the success rate of urban smart growth, it is shown in Figure 1.

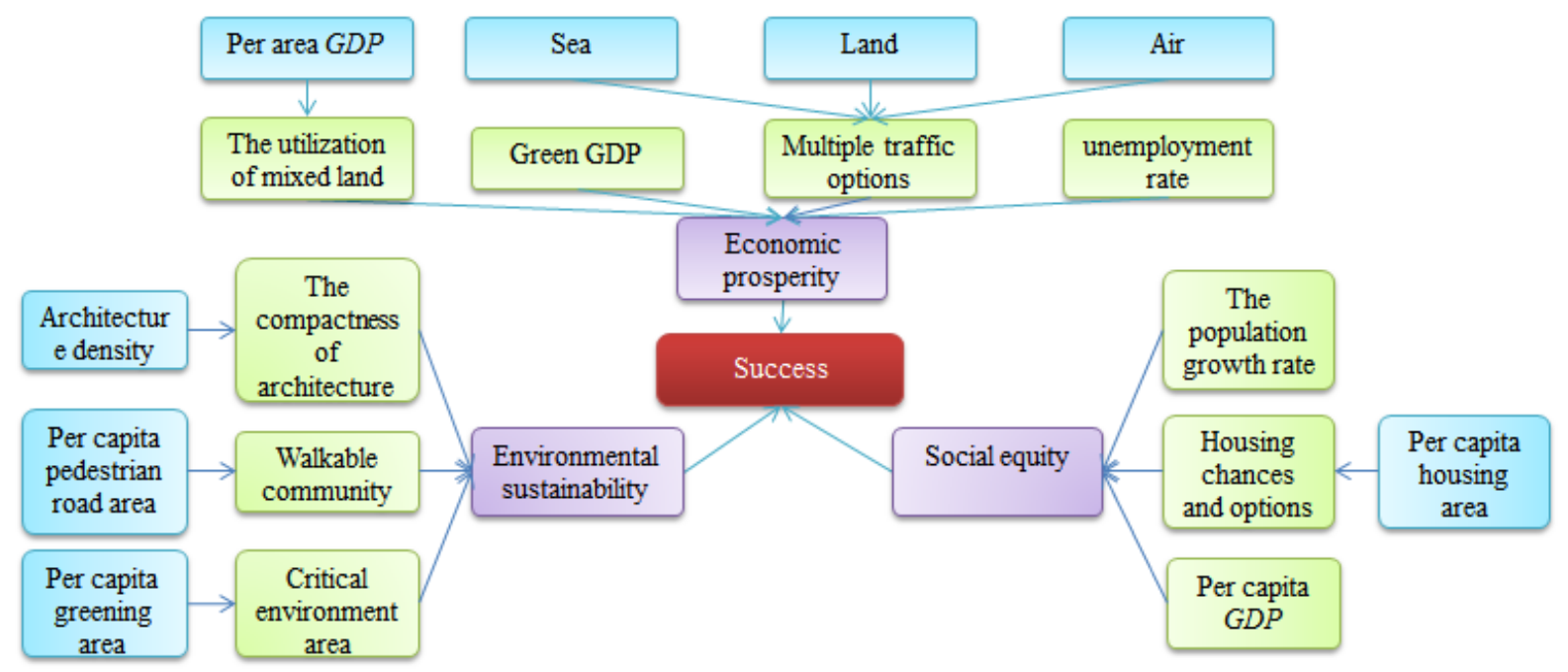

Fig.1 The indexes'hierarchy of measuring urban success rate of smart growth

The two cities in this paper are Jiayuguan City which is from the Asian continent and Salt Lake City of the American continent, we need to consider the three factors of smart growth: $E_{0} / E_{1} / E_{2}$ together with the ten principles of smart growth.Via analyzing the development and changes in the last 5 years of the two cities'indexes of the smart growth, we calculate the success rate of urban smart growth $C I$ (Table 2).

Table. 2 The success rate of urban smart growth

\begin{tabular}{|c|c|c|c|c|c|}
\hline & 2012 & 2013 & 2014 & 2015 & 2016 \\
\hline Jiayuguan City & 0.586677 & 0.633911 & 0.797302 & 0.634740 & 0.724922 \\
\hline Salt Lake City & 0.356778 & 0.512293 & 0.659072 & 0.625194 & 0.672068 \\
\hline
\end{tabular}

\section{The formulation and Evaluation of Smart Growth Plan}

\subsection{Schedule of growth scheme}

In the second model, we analyze the smart growth status of Jiayuguan City and Salt Lake City in detail. Combined with the two cities'geographic location, We found that the importance of each index of the success rate of the urban smart growth needs to be adjusted according to local conditions to meet the requirements of the success rate of smart growth, Therefore, based on the status of urban development, we found six growth plans based on each index:

$>$ Reduce the cost of consumption of environmental decline and improve green GDP;

$>$ Meet the population growth rate and ease the pressure of per capital GDP .

$>$ Improve the utilization of mixed land, promote compact architecture design and then improve the urban per area GDP;

$>$ Preserve open space of the city and improve per capital greening area;

$>$ Increase the help of employment of community residents to improve the degree of cooperation between society and local industrial and per capital GDP;

$>$ With the rapid addition of population, the city needs to increase the housing area to ensure that the citizens have sufficient housing opportunities. 


\subsection{Establishment of the equation of the success rate}

Because each city is different of the geographical conditions, natural environment and resource types. For each city, the importance of each plan is not the same. Therefore, we propose the coefficient of variation, $C$, to deal with the differences of importance from different cities. At this point, the success rate of urban smart growth can be expressed as:

$$
C I=C_{0} \times G+C_{1} \times R+C_{2} \times H+C_{3} \times L+C_{4} \times \alpha_{i}+C_{5} \times J
$$

\subsection{The weight of each growth plan by means of analytic hierarchy process.}

We assume that the six plans are B1, B2, B3, B4, B5, B6. In this paper, firstly, the judgment matrix of the six growth plans of the two cities is formulated according to local conditions.

$$
A_{1}=\left\{\begin{array}{cccccc}
1 & \frac{7}{4} & \frac{7}{5} & 7 & \frac{7}{2} & 7 \\
\frac{4}{7} & 1 & \frac{4}{5} & 4 & 2 & 4 \\
\frac{7}{5} & \frac{5}{4} & 1 & 5 & \frac{5}{2} & 5 \\
\frac{1}{7} & \frac{1}{4} & \frac{1}{5} & 1 & \frac{1}{2} & 1 \\
\frac{2}{7} & \frac{1}{2} & \frac{2}{5} & 2 & 1 & 2 \\
\frac{1}{7} & \frac{1}{4} & \frac{1}{5} & 1 & \frac{1}{2} & 1
\end{array}\right\} \quad A_{2}=\left\{\begin{array}{cccccc}
1 & \frac{4}{5} & \frac{7}{4} & 2 & \frac{4}{3} & 4 \\
\frac{5}{4} & 1 & \frac{5}{7} & \frac{5}{2} & \frac{5}{3} & 5 \\
\frac{1}{2} & \frac{2}{5} & \frac{2}{7} & 1 & \frac{2}{3} & 2 \\
\frac{3}{4} & \frac{3}{5} & \frac{3}{7} & \frac{3}{2} & 1 & 3 \\
\frac{1}{4} & \frac{1}{5} & \frac{1}{7} & \frac{1}{2} & \frac{1}{3} & 1
\end{array}\right\}
$$

Among them, A1, A2 represent the judgment matrix of six growth plans of Jiayuguan City and Salt Lake City, and then calculate the importance of each plan.the rankings of weight of the six growth plans in each city can be obtained (Figure 2).
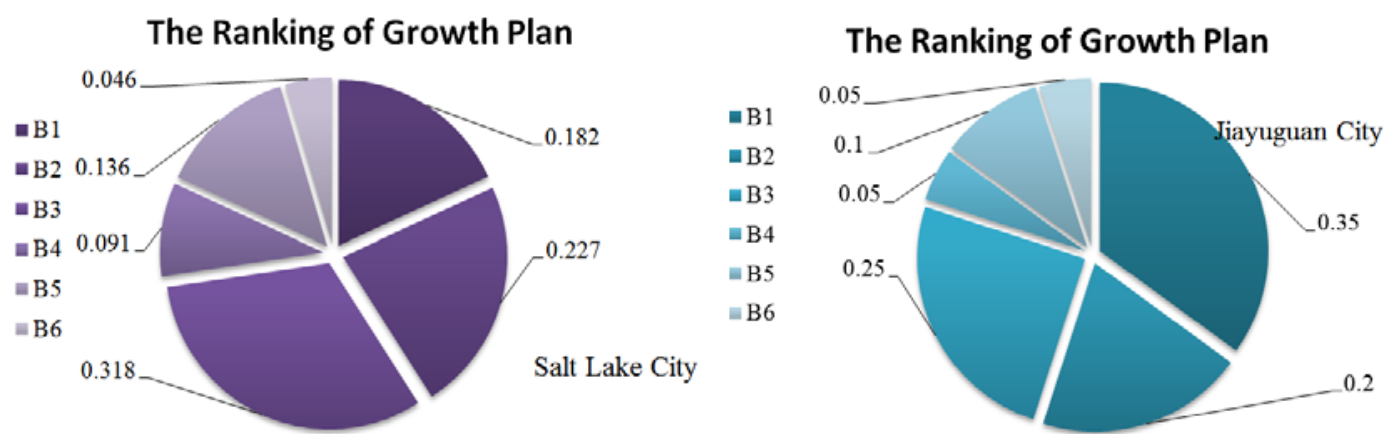

Fig. 2 The rankings of six indexes for Jiayuguan City and Salt Lake City.

\section{Forecast and evaluation model based on GM $(1,1)$}

Based on the data of each index of the two cities in the last 5 years, this paper focuses on the six indexes which are involved in the smart growth plan and forecasts the success rate of urban smart growth of the two cities in the next decade, The paper improves the weght of the six indexes by adjusting the variation coefficient $C$ dynamically and then make the urban six growth plans meet the requirements of urban success rate (Figure 3).

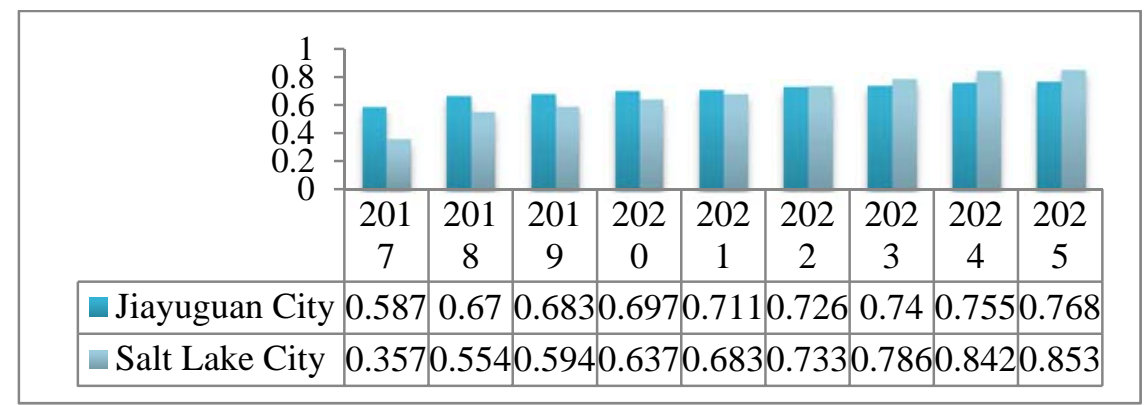

Fig.3 The forecast of the success rate of smart growth of the two cities in the coming years 


\section{Conclusion}

According to the foretasted data of six indexes on the measure of smart growth plan above, we calculate the success rate of urban smart growth of the two cities respectively. The results are shown in Fig 3.Via the analysis we can see:

$>$ In 2024, the success rate of smart growth of Jiayuguan City is 0.75531> 0.75, It is in line with the standard idea of sustainable development

$>$ In 2023, the success rate of smart growth of Salt Lake City is $0.78552>0.75$. It will be in line with the idea of urban sustainable development.

\section{References}

[1]. Yin Boyue. Study and Application on the Evaluation Indicator System of City Sustainable Development [D]. Beijing: University of Science and Technology Beijing, 2003.

[2]. Zhang Rong. Studies on Dynamics Model and Evaluation Index System of Urban Sustainable Development [D]. Henan: Henan Agricultural University, 2003.

[3]. Edward J. Jepson Jr; Mary M. Edwards. How possible is Sustainable Urban Development? An Analysis of Planners' Perceptions about New Urbanism, Smart Growth and the Ecological. City. Planning [J]. Practice \& Research. Volume 25, Issue 4, 2010 pages 417-437. 